\title{
PERBEDAAN INDEKS PLAK SEBELUM DAN SESUDAH PENGUNYAHAN BUAH APEL
}

\author{
${ }^{1}$ Preazy Agung C. Penda, \\ ${ }^{2}$ Stefana H. M. Kaligis, \\ ${ }^{3}$ Juliatri
}

\author{
${ }^{1}$ Kandidat Skripsi Program Studi Pendidikan Dokter Gigi Fakultas Kedokteran, \\ ${ }^{2}$ Bagian Biokimia Fakultas Kedokteran, \\ ${ }^{3}$ Program Studi Pendidikan Dokter Gigi Universitas Sam Ratulangi \\ Email: agungpenda63@gmail.com
}

\begin{abstract}
Teeth and mouth are important parts in human body. In order to perform its function properly, dental and oral hygiene need to be considered. Dental and oral hygiene can be observed from the formation of plaque. The effort to prevent plaque formation is called plaque control. Plaque control can be done naturally by masticating fibrous foods, inter alia apple. This study aimed to determine whether there were any difference in plaque index between before and after masticating an apple. Samples were collected by using total sampling method. There were 44 samples, obtained from 72 students of Senior High School Sorong, West Papua. The results showed that the average of plaque index before and after masticating an apple was 2.1 and 1.2. The paired sample t-test showed a $\mathrm{P}$ value of 0.000 . Conclusion: There was a significant difference in plaque index before and after masticating an apple.
\end{abstract}

Keywords: plaque index, masticating, apple

\begin{abstract}
Abstrak: Gigi dan mulut merupakan bagian penting dalam tubuh manusia.Agar dapat menjalankan fugsinya dengan baik, kesehatan gigi dan mulut perlu diperhatikan.Tingkat kebersihan gigi dan mulut dapat dilihat dari pembentukan plak.Upaya pencegahan timbulnya plak disebut dengan kontrol plak.Kontrol plak dapat dilakukan secara alamiah yaitu dengan mengunyah makanan berserat, salah satunya adalah buah apel. Penelitian ini bertujuan untuk mengetahui apakah terdapat perbedaan indeks plak sebelum dan sesudah pengunyahan buah apel. Metode yang digunakan dalam penelitian ini ialah metode Pra eksperimental dengan rancangan pretest and posttest one group only yang dilakukan pada siswa kelas XI SMA Negeri 1 Sorong Papua Barat. Metode pengambilan sampel yang digunakan ialah total sampling dengan jumlah responden 44 dari 72 siswa. Hasil penelitian menunjukkan rerata indeks plak sebelum pengunyahan buah apel ialah 2,1 dan rerata indeks plak sesudah pengunyahan buah apel ialah 1,2. Analisis data menggunakan uji paired t-test menunjukkan $\mathrm{P}$ $=0,000$. Simpulan: Terdapat perbedaan yang signifikan antara indeks plak sebelum dengan sesudah pengunyahan buah apel.
\end{abstract}

Kata kunci: indeks plak, pengunyahan, buah apel

Gigi dan mulut merupakan bagian penting dalam tubuh manusia.Gigi terdapat dalam rongga mulut dan memiliki berbagai fungsi. Agar dapat menjalankan fungsinya dengan baik kesehatan gigi dan mulut perlu diperhatikan. Keadaan gigi yang rusak dapat berdampak pada kesehatan tubuh lainnya dan berpengaruh pada estetik seseorang. Karies gigi dan penyakit periodontal merupakan penyakit gigi dan mulut yang banyak ditemui pada masyarakat. Hasil dari data Riset Kesehatan Dasar tahun 2013 oleh Departemen Kesehatan menunjukkan 
bahwa masalah gigi dan mulut dijumpai sebesar 25,9\%. ${ }^{1}$

Mulut merupakan tempat yang ideal bagi perkembangan bakteri karena temperatur, kelembaban dan makanan yang cukup tersedia. ${ }^{2}$ Memiliki gigi dan mulut yang sehat selain akan menghindarkan dari bakteri yang sering menimbulkan berbagai keluhan sakit gigi, juga akan menjaga kesegaran aroma mulut dan menjadikan senyum terlihat lebih menawan. Penelitian juga menunjukkan bahwa mulut yang sehat dapat membantu mencegah penyakit jantung dan sejumlah penyakit lainnya. ${ }^{2}$

Tingkat kebersihan gigi dan mulut dapat dilihat dari proses pembentukan plak. Plak merupakan faktor etiologi utama terjadinya karies dan penyakit periodontal karena mengandung bakteri patogen yang melekat pada permukaan gigi dan gingiva. ${ }^{3}$ Plak terjadi ketika makanan yang mengandung karbohidrat (gula dan zat tepung) seperti susu, minuman ringan, kismis, kue, atau permen tersisa pada gigi. Upaya dalam mencegah penyakit gigi dan mulut serta meningkatkan kebersihan mulut dapat dilakukan dengan mencegah dan menghilangkan akumulasi plak. ${ }^{4}$ Upaya pencegahan timbulnya plak disebut dengan kontrol plak.

Terdapat beberapacara yang digunakan dalam kontrol plak yaitu mekanik, kimiawi dan alamiah. ${ }^{5}$ Sampai saat ini, kontrol plak masih mengandalkan pembersihan secara mekanik. Kontrol plak secara mekanik adalah dengan cara menyikat gigi. Kemampuan menyikat gigi secara baik dan benar merupakan faktor yang cukup penting untuk pemeliharaan kesehatan gigi dan mulut. ${ }^{6}$ Untuk mencapai keberhasilan dalam memelihara kesehatan gigi dan mulut juga dipengaruhi oleh faktor penggunaan alat, metode penyikatan gigi, serta frekuensi dan waktu penyikatan yang tepat. Jika semua ini dapat dilakukan secara terus-menerus keberhasilan dalam menjaga kesehatan gigi dan mulut dapat tercapai dan keinginan memiliki gigi dan mulut yang sehat dan senyum yang indah dapat terwujud. ${ }^{7,8}$ Kontrol plak secara kimiawi adalah dengan cara berkumur dengan cairan anti bakteri. Berkumur menggunakan cairan antibakteri dapat membunuh bakteri yang menempel pada permukaan gigi.

Kontrol plak secara alamiah adalah dengan cara mengunyah makanan berserat. ${ }^{8}$ Kebiasaan makan makanan berserat bersifat sebagai pengendali plak secara alamiah. ${ }^{8}$ Makanan padat dan berserat secara fisiologis akan meningkatkan intensitas pengunyahan dalam mulut. Proses pengunyahan makanan ini akan merangsang dan meningkatkan produksi saliva. Saliva akan membantu membilas gigi dari partikel-partikel makanan yang melekat pada gigi dan juga melarutkan komponen gula dari sisa makanan yang terperangkap dalam sela-sela pit dan fisur permukaan gigi.Beberapa buah segar, setengah matang, berair, dan berserat dapat membantu menurunkan indeks plak, salah satunya adalah buah apel. Mengunyah buah apel dapat memberi efek positif pada kesehatan gigi. Mengunyah apel sering disebut cara alami menyikat gigi, karena apel mempunyai partikel besar yang harus dikunyah lagi sebelum ditelan, dan juga apel merupakan buah yang mengandung serat sehingga mendorong sekresi saliva. ${ }^{6,9}$

Berdasarkan latar belakang di atas peneliti tertarik untuk melakukan penelitian ini pada siswa kelas X SMA Negeri 1 Sorong Papua Barat karena pada usia 16-18 tahun mereka telah mempunyai gigi permanen kecuali M3 sehingga pertumbuhan plak mulai tidak terkontrol. Selain itu di sekolah tersebut belum pernah dilakukan penelitian dan penyuluhan tentang kesehatan gigi dan mulut. Minimnya tingkat pengetahuan masyarakat tentang kesehatan gigi dan mulut, oleh karena kurangnya tenaga kesehatan gigi di kota Sorong juga menjadi alasan di pilihnya lokasi penelitian dan adanya kerja sama yang baik dari pihak sekolah dalam kelangsungan penelitian ini.

\section{BAHAN DAN METODE PENELITIAN}

Desain penelitian yang digunakan dalam penelitian ini yaitu desain penelitian praeksperimental dengan memeriksa 
indeks plak awal (pretest) dan sesudah dilakukan perlakuan dengan memeriksa indeks plak akhir (posttest).

Penelitian ini dilakukan di SMAN 1 Sorong Papua Barat pada bulan MeiAgustus 2015.Populasi pada penelitian ini ialah siswa kelas X SMA Negeri 1 Sorong Papua Barat. Sampel yang digunakan ialah seluruh siswa kelas $\mathrm{X}$ yang berjumlah 72 siswa, dengan teknik pengambilan sampel secara total sampling. Bahan yang digunakan ialah buah apel 50 gram/Responden, disclosing solution, alkohol 70\%, air, dan kapas.

Pemeriksaan gigi pada siswa dengan menggunakan disclosing solution, kaca mulut, dan sonde. Setelah dilakukan pemeriksaan indeks plak awal, peneliti memberikan buah apel sebanyak 50 gram/responden untuk dikunyah dengan memberikan instruksi pengunyahan. Setelah selesai melakukan pengunyahan buah apel, langsung diukur indeks plak akhir dari

Penelitian ini dilakukan pada MeiAgustus 2015 di SMA Negeri 1 Sorong Papua Barat. Sekolah ini terletak di kecamatan Kampung Baru, Kelurahan Sorong Barat, di Kota Sorong, Provinsi Papua Barat.

\section{HASIL PENELITIAN DAN BAHASAN}

Tabel 1. Distribusi karakteristik responden berdasarkan jenis kelamin sampel

\begin{tabular}{ccc}
\hline $\begin{array}{c}\text { Jenis } \\
\text { Kelamin }\end{array}$ & Jumlah & $\%$ \\
\hline Laki-laki & 18 & 40,9 \\
Perempuan & 26 & 59,1 \\
Total & 44 & 100,0 \\
\hline
\end{tabular}

Berdasarkan hasil penelitian diperoleh responden berjumlah 72 siswa, namun yang memenuhi kriteria inklusi sebanyak 44 siswa. Berdasarkan jenis kelamin responden terbanyak ialah perempuan (59,1\%) (Tabel 1).

Berdasarkan usia responden 15-17 tahun didapatkan usia yang paling banyak adalah usia 16 tahun dengan persentase
45,5\% dan usia yang paling sedikit adalah usia 15 tahun dengan persentase 15,9\% (Tabel 2).

Tabel 2. Distribusi karakteristik responden berdasarkan usia

\begin{tabular}{ccc}
\hline Usia & $\mathrm{n}$ & $\%$ \\
\hline 15 & 7 & 15,9 \\
16 & 20 & 45,5 \\
17 & 17 & 38,6 \\
Total & 44 & 100,0 \\
\hline
\end{tabular}

Hasil pemeriksaan indeks plak gigi sebelum dilakukan pengunyahan buah apel didapatkan nilai maximum 2,8, minimum 1,6, median 2,1, mean 2,114 dengan standar deviation 0,2664.

Tabel 3. Hasil pemeriksaan indeks plak gigi sebelum pengunyahan buah apel

\begin{tabular}{cccc}
\hline $\begin{array}{c}\text { Indeks } \\
\text { plak }\end{array}$ & Kategori & $\mathrm{n}$ & $\%$ \\
\hline 0 & $\begin{array}{c}\text { Sangat } \\
\text { baik }\end{array}$ & 0 & 0 \\
$0,1-0,9$ & Baik & 0 & 0 \\
$1,0-1,9$ & Sedang & 11 & 25,0 \\
$2,0-3,0$ & Buruk & 33 & 75,0 \\
Total & & 44 & 100,0 \\
\hline
\end{tabular}

Berdasarkan kategori indeks plak sebelum pengunyahan buah apel didapatkan hasil bahwa11 siswa yang memiliki indeks plak pada ketegori sedang dengan persentase sebesar 25,0\%, dan sebanyak 33 siswa memiliki indeks plak pada kategori buruk dengan persentase sebanyak 75,0\% (Tabel 3). Hasil pemeriksaan indeks plak sesudah pengunyahan buah apel didapatkan nilai maximum 1,9 , minimum 0,5 , median 1,2 , mean 1,152 dengan standardeviation 0,3015.

Berdasarkan kategori indeks plak sesudah pengunyahan buah apel pada siswa SMA Negeri 1 Sorong, maka didapatkan hasil sebanyak 13 siswa yang memiliki indeks plak dengan kategori baik dengan persentase sebesar 29,5\%, sedangkan sebanyak 31 siswa memiliki indeks plak untuk ketegori sedang dengan persentase 
sebesar 70,5\%. Tabel 4 menunjukkan hasil penelitian pemeriksaan indeks plak sesudah dilakukan pengunyahan buah apel.

Tabel 4. Hasil pemeriksaan indeks plak gigi sesudah pengunyahan buah apel

\begin{tabular}{cccc}
\hline Indeks plak & Kategori & $\mathrm{n}$ & $\%$ \\
\hline 0 & Sangat & 0 & 0 \\
& baik & & \\
$0,1-0,9$ & Baik & 13 & 29,5 \\
$1,0-1,9$ & Sedang & 31 & 70,5 \\
$2,0-3,0$ & Buruk & 0 & 0 \\
Total & & 44 & 100,0 \\
\hline
\end{tabular}

Pada uji normalitas data menggunakan uji Shapiro-Wilk didapatkan data terdistribusi normal. Dengan uji paired $t$ test diperoleh hasil $\mathrm{p}=0,000$ (Tabel 5) yang menunjukkan terdapat perbedaan yang signifikan antara indeks plak sebelum dan sesudah pengunyahan buah apel.

Tabel 5. Distribusi rata-rata indeks plak gigi sebelum dan sesudah pengunyahan buah apel

\begin{tabular}{cccc}
\hline $\begin{array}{c}\text { Mea } \\
\mathrm{n}\end{array}$ & $\begin{array}{c}\text { Std } \\
\text { Deviati } \\
\text { on }\end{array}$ & $\begin{array}{c}\text { Std } \\
\text { Error }\end{array}$ & Sig \\
\hline 2,11 & 0,27 & 0,266 & 0,0 \\
4 & & 4 & 0 \\
1,15 & 0,30 & 0,301 & \\
2 & & 5 & \\
\hline
\end{tabular}

\section{BAHASAN}

Berdasarkan hasil analisis data diperoleh skor rerata indeks plak sebelum melakukan pengunyahan ialah 2,114 (Tabel 8), dan skor rerata indeks plak sesudah pengunyahan buah apel sebesar 1,152 (Tabel 8). Hasil analisis data menggunakan uji paired t-test dapat dinyatakan bahwa terdapat perbedaan hasil yang signifikan antara indeks plak sebelum dan sesudah pengunyahan buah apel pada siswa SMA Negeri 1 Sorong Papua Barat. Hasil penelitian ini sejalan dengan penelitian yang dilakukan oleh Ramdhani AR pada mahasiswa Universitas Muhammadyah Yogyakarta mengenai efek pengunyahan buah apel dan pir dalam menurunkan jumlah plak.Penelitian yang dilakukan oleh Ramdhani AR ialah dengan membandingkan dua jenis buah yaitu apel dan pir dan setiap mahasiswa mendapat dua perlakuan yaitu mengunyah buah apel dan pir. Indeks plak dinilai sebelum dan sesudah mengunyah menggunakan Plaque Control Record dan pada penelitian tersebut diperoleh kesimpulan adanya pengaruh penurunan indeks plak pada pengunyahan buah apel dan pir tetapi tidak terdapat perbedaan yang bermakna antara keduanya. $^{10}$ Penelitian mengenai efek pengunyahan buah berserat juga dilakukan pada remaja usia 12 tahun di Panti Asuhan Yayasan Nur Hidayah Surakarta. Pada penelitian tersebut menggunakan buah stroberi yang akan dikonsumsi oleh responden. Hasil penelitian tersebut adalah mengunyah buah stroberi dapat menghambat pertumbuhan jumlah plak gigi pada remaja usia 12 tahun di Panti Asuhan Yayasan Nur Hidayah Surakarta. ${ }^{11}$

Perbedaan indeks plak sebelum dan sesudah pengunyahan buah berserat juga pernah dilakukan oleh Sunomo pada siswasiswi SDN Taquma Surabaya. Dalam penelitian tersebut Sunomo menggunakan dua jenis buah yaitu buah apel dan jambu merah. Hasil penelitian yang dilakukan oleh Sunomo rata-rata skor indeks plak sebelum pengunyahan buah apel sebesar 3,5 dan rata-rata skor indeks plak sesudah pengunyahan buah apel ialah 2,31. Sebelum pengunyahan buah jambu merah rata-rata skor indeks plak 3,81 dan rata-rata skor indeks plak sesudah pengunyahan buah jambu merah sebesar 1,93. Kesimpulan dari hasil penelitian tersebut ialah buah apel dan jambu merah efektif dalam menurunkan angka skor plak. ${ }^{12}$

Kontrol plak sampai saat ini masih mengandalkan kontrol plak secara mekanis. Kontrol plak secara mekanis adalah dengan menggunakan sikat gigi. Kontrol plak juga bisa dilakukan secara kimiawi yaitu dengan berkumur menggunakan cairan antibakteri. Dalam penelitian ini peneliti mengunakan kontrol plak secara alamiah yaitu dengan cara mengunyah buah berserat. Dalam penelitian ini peneliti menggunakan buah 
apel seberat 50 gram yang diberikan satu kali kepada responden untuk dikunyah. Buah apel ialah salah satu makanan berserat yang diketahui dapat membersihkan sisa makanan yang menempel pada gigi. Buah apel memiliki kandungan tannin berkonsentrasi tinggi yang dapat mencegah kerusakan gigi dan penyakit gingiva yang disebabkan oleh penumpukan plak. Kerenyahan dan kandungan serat pada buah apel dapat membantu membersihkan sisa-sisa makanan yang melekat pada gigi, karena apel merupakan buah berserat sehingga mengunyah buah apel bisa disebut sebagai sikat gigi secara alamiah. Dalam pengunyahan buah apel memerlukan tekanan gigitan yang cukup kuat sehingga intensitas pengunyahan akan meningkat dan memicu keluarnya saliva. Keluarnya saliva dan dibantu dengan kandungan air yang terdapat didalam buah apel mampu membersihkan sisa makanan yang menempel pada permukaan gigi. ${ }^{10}$ Berdasarkan hasil penelitian diatas pada pemeriksaan plak awal sebelum dilakukan pengunyahan buah apel didapatkan 33 responden memiliki indeks plak dengan kategori buruk. Pada pemeriksaan indeks plak akhir setelah pengunyahan buah apel didapatkan 31 responden memiliki indeks plak dengan kategori sedang. Penurunan indeks plak pada siswa SMA Negeri 1 Sorong Papua Barat disebabkan karena peneliti memberkan buah apel untuk dikunyah oleh responden. Kandungan serat pada buah apel membantu membersihkan plak yang menempel pada gigi.

Limitasi penelitian ini yaitu penelitian hanya dilakukan pada siswa kelas $\mathrm{X}$, karena keterbatasan waktu yang diberikan oleh pihak sekolah sehingga siswa kelas XI, dan XII tidak bisa diikut sertakan dalam penelitian, untuk itu perlu adanya penelitian lanjutan di SMANegeri 1 Sorong Papua barat dengan jumlah responden yang lebih banyak.

\section{SIMPULAN}

Berdasarkan hasil penelitian di SMA Negeri 1 Sorong Papua Barat dapat disimpulkan bahwa pengunyahan buah apel yang dilakukan oleh siswa kelas X SMA Negeri 1 Sorong Papua Barat dapat menurunkan indeks plak.

\section{SARAN}

1. Perlu adanya upaya berkelanjutan dari tenaga kesehatan kedokteran gigi untuk terus memberikan penyuluhan dan pengetahuan bagi para siswa SMA Negeri 1 Sorong Papua Barat secara khusus dan masyarakat pada umumnya mengenai cara kontrol plak gigi terutama dengan mengunyah buah berserat seperti buah apel.

2. Perlu adanya penelitian lanjutan mengenai cara kontrol plak gigi dengan mengonsumsi buah berserat.

\section{DAFTAR PUSTAKA}

1. Departemen kesehatan Republik Indonesia. Laporan hasil riset kesehatan dasar (Riskesdas) nasional 2013. Jakarta: Kementrian Kesehatan RI; 2013

2. Ratih L. Hubungan kebersihan mulut dengan penyakit sistemik dan usia harapan hidup. Poltekes-Denpasar Journal of Dentistry 2010. p.2-3

3. Edwina AM, Kidd, Sally J. Dasar-dasar karies penyakit dan penanggulangannya. Jakarta: Penerbit buku kedokteran EGC; 1992 p.2-3.

4. Nurjannah MH, Eliza $H$, Neneng. Ilmu pencegahan penyakit jaringan keras dan jaringan pendukung gigi: Penerbit Buku Kedokteran EGC:2009.p.53-90

5. Putti FD, Restadiamawati. Pengaruh konsumsi permen karet yang mengandung xylitol terhadap pembentukan plak gigi [karya tulis ilmiah]. Semarang: Universitas Diponegoro. April 22, 2015. p.2-3

6. Ismu SS. Petunjuk paraktis system merawat gigi anak di klinik. Penerbit buku kedokteran. EGC. 2010. p.10-1

7. Eliza H, Tati SI, Sri A. Pendidikan kesehatan gigi. Penerbit buku kedokteran. EGC. 2002. p.26-9.

8. Michael W, Ticoalu SHR, Juliatri. Gambaran Kebersihan Mulut dan Karies Gigi Pada vegetarian LactoOvo di Jurusan Keperawatan Universitas Klabat Airmadidi. Jurnal e-GiGi. 2015;(3);116.

9. Ajeng RR. Efektivitas Pengunyahan Buah 
Penda, Kaligis, Juliatri: Perbedaan indeks plak...

Apel (pyrus malus) dan Buah Pir (pyrus Communis L) Terhadap Penurunan Plak. Undergraduate Theses from YOPTUMYFKPP/201206-13;24-54

10.Novan KM. Pengaruh mengunyah buah stroberi terhadap hambatan pembentukan plak gigi pada remaja usia 12-18 tahun di panti asuhan yayasan Nur Hidayah kota Surakarta. Surakarta: FKG UMS; 2014.

11.Sunomo H. Perbedaan efektifitas pemberian buah apel dan jambu merah dalam menurunkan angka plak indeks pada siswa kelas V SDN Taquma Surabaya. Poltekkes-mks. 2015 
Jurnal e-GiGi (eG), Volume 3, Nomor 2, Juli-Desember 2015 